\title{
Conjunctive Use Modeling of Groundwater and Surface Water
}

\author{
Hosein Mahjoub, Mohammad Mahdi Mohammadi*, Masoud Parsinejad \\ Department of Irrigation and Reclamation Engineering, University of Tehran, Karaj, Iran \\ E-mail: ${ }^{*}$ t_mohamadi@yahoo.com \\ Received August 8, 2011; revised September 9, 2011; accepted October 12, 2011
}

\begin{abstract}
In this study, conjunctive use of surface and groundwater in the Maraghe area was investigated. The objective function used for the overall conjunctive use model was maximizing sum of relative yields of crops in the command area. Declining groundwater levels was selected as criteria of groundwater limitation. The simulation was done for four years and began by a dry year to normal year. GMS software was used to simulate groundwater aquifer. In this model, different well discharges in the study area for different scenarios were used and decline in groundwater level at the end of simulation time was calculated. In order to model surface water and calculate the objective function, a program in Visual Basic was developed. Two types of scenario, annual and seasonal, were defined by specifying the ratio of the allocation of surface water to that of groundwater pumping at the crop level for entire irrigated area. For different scenarios, declining groundwater levels and objective functions were calculated. With attention to maximize objective function that the water table drawdown is not greater than the limited criterion, the best scenario was obtained. In annual scenarios, The results showed that in scenario of 75 - 25 (75\% surface water to $25 \%$ groundwater), the purpose function rate was 12.2 and water table draw down was 2.6, which was lower than allowable limitation. Therefore, it was chosen as a selective scenario. Also in seasonal scenarios, The best scenario was chosen 100-40-60 (the percentage of surface water share in spring, summer and fall \& winter respectively), which amount of purpose function was 12.57 and the water table draw down was around $3 \mathrm{~m}$ at the end of the simulation period.
\end{abstract}

Keywords: Conjunctive Use, Relative Crop Yield, Surface and Groundwater Resources, Model

\section{Introduction}

Iran with atmospheric raining average of $260 \mathrm{~mm}$ per year is one of the arid countries of the world with limited water resources. Factors like population growth, more demands for food, necessity of higher sanitation level and social welfare promotion, industrial development and ecosystem protection, have increased the water demand day by day. Annually, renewal water resources per capita decrease according to population growth in Iran.

Shortage of surface water resources and being insufficient of these resources for additional water requirement has been led to inevitable using of groundwater resources. Unlimited offtake of groundwater aquifers in cities and plains and subsequent problems force an experts to sup- ply the needs by the other methods.

One of the new techniques in present century in management part is optimum conjunctive use of surface and groundwater. Hydrological connections between surface water and groundwater are an intrinsic component of the hydrological processes on the catchment scale.

Conjunctive use is called the management of surface water and groundwater resources which are used simultaneously [1]. The accomplished research in conjunctive use are divided to three parts of quantitative, qualitative and quantitative-qualitative. In quantitative method, the goal is determining the removal amount of water and temporal and spatial distribution of offtake from each resources in order to decrease shortages, water storing in groundwater aquifers which are near to disposal places, more desirable management of irrigation requirement in 
drought time and omission or decrease of problems related to drainage [1]. In qualitative method, most of the studies have been done in field of irrigation networks and conjunctive use of water with low and high quality [2]. Finally in qualitative-quantitative part, most of the studies had been in term of urban piping and supplying the water in desirable quality [3].

By considering the fact that most of our country plains have a problem in term of water resources, conjunctive use can be considered as a proper technique for water security. The casestudy in this direction is conjunctive use of surface water and groundwater for irrigation of Tehran plain lands with aims of decrease water shortage rate for supply irrigation requirement, decrease pomping cost and control of water table depth in groundwater aquifers [4].

The conjunctive use scenarios are defined by determining the proportion of surface water which is allocated from reservior to the amount of groundwater pumping (for irrigation of arable lands). The proportion of these two in modeling is taken into account as a scenario. It is called the stable scenario which water table draw down changes of groundwater don't exceed of allowable amount for desirable performance. In a research in Jordan drainage basin in Utah state, after modeling of regional surface and groundwater, different scenarios of development for supplying of now and future water demands in form of: 1) Developing of surface water sources 2) developing of surface and groundwater sources separately 3) Conjunctive development of ground and surface water resources were simulated. Among these choices, integrated development of water resources chose as superior choice [5]. Belaineh et al. [6] presented the simulation- optimization model that integrates linear reservoir decision rules, detailed simulations of stream/aquifer system flows, conjunctive use of surface and groundwater, and delivery via branching canals to water users. State variables, including aquifer hydraulic head, streamflow, and surface water/aquifer interflow, are represented through discretized convolution integrals and influence coefficients. Reservoir storing and branching canal flows and interflows are represented using embedded continuity equations. Results of application indicate that the more detail used to represent the physical system, the better the conjunctive management. Azaiez and Hariga, [7] developed a model for a multi-reservoir system, where the inflow to the main reservoir and the demand for irrigation water at local areas are stochastic. High penalty costs for pumping groundwater are imposed to reduce the risk of total depletion of the aquifer as well as quality degradation and seawater intrusion. The problem is analyzed for a single period with a single decisionmaker approach. Deficit irrigation is allowed in maxi- mizing expected total profit for the entire region. A nonlinear stochastic problem with linear constraints is formulated and an iterative procedure that generates an optimal operating scenario is proposed. Model application is illustrated with a hypothetical example. ChengShin Jang and Jui-Sheng Chen [8] evaluated combination of groundwater and surface water flow for optimizing of agricultural consumption for surface water shortage during one period of long term drought in chiyanan plain in south eastern region of Taiwan. This mixing took place on basis of irrigation water quality standard. Results showed that after proper mixing of groundwater with sur- face water ( $0.5 \& 0.25$ ), $48 / 9 \%$ of this plain can supply irrigation requirement by conjunctive use. Understanding of the interactions between surface and groundwater flow and the integral simulation of both streams are important for conjunctive resources management $[9,10]$.

In this study, method of research and operation which was used for conjunctive use of surface and groundwater needs a region in which there is a reservoir, groundwater aquifer and agricultural lands. Therefore, the Maraghe plain was chosen because of Alavian dam, qroundwater aquifer and agricultural lands called Sufichay.

\section{Materials and Methods}

\subsection{Study Area}

\section{General Characteristics}

The study area, named Maraghe plain, is situated in Northwestern of Iran, southern slopes of Sahand mountains and southeastern of Uromiyeh lake. Also it has been located in distance of $120 \mathrm{~km}$ of southwestern of Tabriz city, between $46^{\circ}$ to $46^{\circ} 11^{\prime}$ eastern length and $37^{\circ} 11^{\prime}$ to $37^{\circ} 28^{\prime}$ northern width. Maraghe and Bonab cities are two major cities located in the research area which are shown in Figure 1.

\subsection{Surface Water of Region}

Permanent river of Sufichay is the main surface resource for supplying agricultural and drinking water demands in the region [11]. This river orginates from the south slope of Sahand peak and its around heights. Alavian reservoir dam with height of $70 \mathrm{~m}$ from river basin and reserve volume of 60 million $\mathrm{m}^{3}\left(\mathrm{~S}_{\max }\right)$ has been built on this reiver. The dead volume of dam is 3 million $\mathrm{m}^{3}$ which is considered as $S_{\min }$ [12]. At the beginning of modeling, reservoir volume was considered equal to the reserved volume $\left(S_{\max }\right)$. Tables 1 and $\mathbf{2}$ present the monthly average discharge of sufichay river and amount of effective rainfall in Sufichay plain, respectively. 


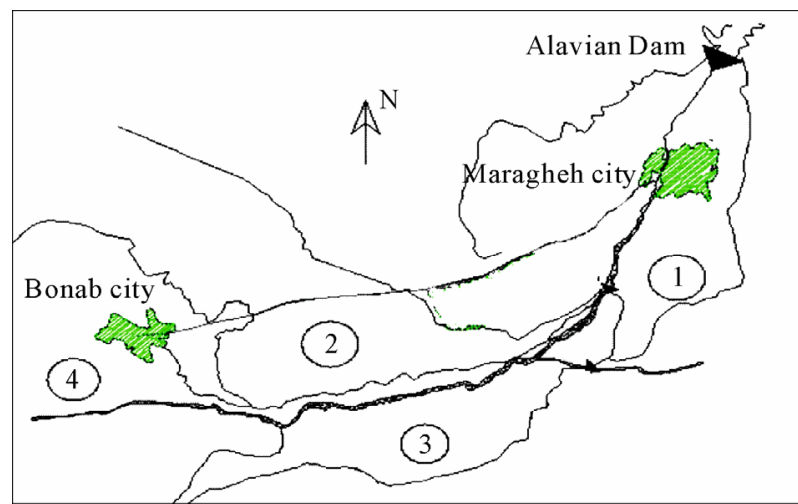

Figure 1. Localizing the agricultural lands (No. 1 to 4 ) and cities in Sufichay plain.

\subsection{Groundwater of Region}

Maraghe plain watershed is the largest groundewater resource of the study area. This watershed was formed by percipitation of plain sediments during activity in different cycles of pedology, begins from southern end of Maraghe city and develops along eastern-western and finally reaches to Uromiyeh lake. For modeling the groundwater aquifer, it was used the available groundwater modeling of Maraghe plain [11]. The Pumping rate from observatory wells for different Conjunctive use scenarios has been specified and the average amount of water table draw down in aquifer was determined by using the GMS software. In this software, Geographical Information System (GIS) was used for data management, processing and information output.

\subsection{Conjunctive Use}

The main components of conjunctive use system are consist of reservoir, Irrigated agricultural lands and groundwater aquifer. Dynamic relationships and the mathematical formulas between components specify their mutual effect on each other.

Optimum scenario of conjunctive use from surface and groundwater resources will be achieved for irrigation of arable land by using mutual relations between component and development of mathematical relations controlling over them. In Figure 2, general sketch of conjunctive use system has been shown from supplying water resources.

For decision making, it must be defiened a proper purpose function for reservoir offtake, pumping rate of availabe wells in the region, and specifying the availabe water in different growth periods of plants. Different parameters interface in definition of this function. For creating hydrologic-economic modeling with aim of optimizing the conjunctive use of surface and groundwater in study of Adra river basin in spain, maximization of the economic profit for water consumers was chosen as a purpose function. In this model, the condition of available water resources in the area applied in form of limitation. After modeling, different scenarios and their effects on area were considered. Among the defined scenarios, conjunctive use was chosen as a best scenario to decrease the obtainable costs and increase the profit for water consumers [13]. Also for integrated management of surface and groundwater resources in irrigation of Indian arable lands, the purpose function was chosen for maximizing of relative crop yield of all crops in each year by considering the bonds and restrictions, applied in model [14].

In this study, the purpose function is maximizing the relative crop yields during the modeling period. If the goal is yeild production on the basis of crop yield weight, the maximum amount will be achieved when there is no water tension during the growth stages. The lack of water during the plant growth stages, cause decrease the crop yield weight. This maximizing is possible with attention to limitation such as weight balance in reservoir, connection of soil humidity for each crop and dominant equations on groundwater flow.

\subsubsection{Crop Yield Optimizing}

Conjunctive use modeling for irrigation requires inter-

Table 1. The monthly average discharge of sufichay river.

\begin{tabular}{lcccccccccccc}
\hline \multicolumn{1}{c}{ Season } & \multicolumn{3}{c}{ Spring } & \multicolumn{3}{c}{ Summer } & \multicolumn{3}{c}{ Fall } & \multicolumn{3}{c}{ Winter } \\
\hline Iranian Months & Far. & Ord. & Kho. & Tir & Mor. & Sha. & Meh. & Aba. & Aza. & Day & Bah. & Esf. \\
Avareage discharge $\left(\mathrm{m}^{3} / \mathrm{s}\right)$ & 9.01 & 14.17 & 10.06 & 2.9 & 1.33 & 1.02 & 1.31 & 1.52 & 1.48 & 1.44 & 1.44 & 2.36 \\
\hline
\end{tabular}

Table 2. The amount of effective rainfall in sufichay plain.

\begin{tabular}{|c|c|c|c|c|c|c|c|c|c|c|c|c|}
\hline Season & & Spring & & & umme & & & Fall & & & Wintel & \\
\hline Iranian Months & Far. & Ord. & Kho. & Tir & Mor. & Sha. & Meh. & Aba. & Aza. & Day & Bah. & Esf. \\
\hline Effective rainfall (mm) & 41 & 26.5 & 4.5 & 0 & 0 & 1 & 11.5 & 12.5 & 16 & 15.5 & 13 & 21 \\
\hline
\end{tabular}




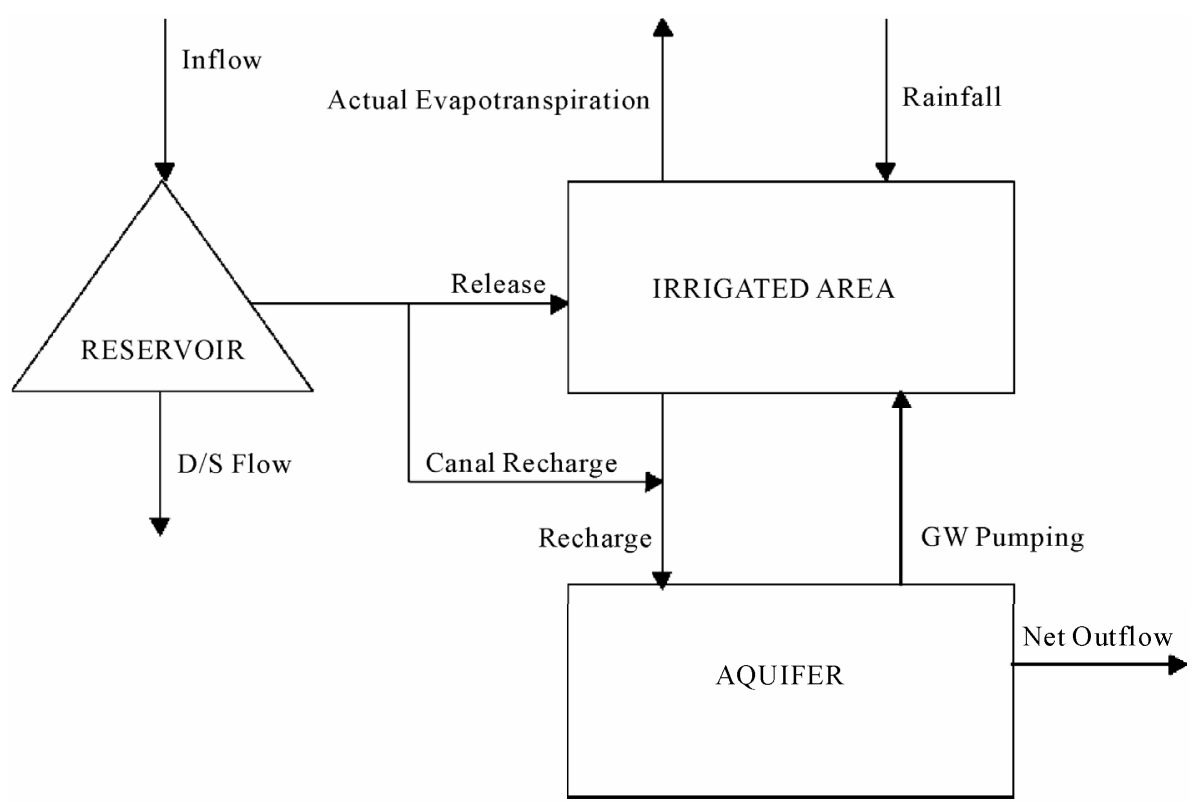

Figure 2. General sketch of modeling.

facing of reservoir operation, soil moisture accounting and ground water balance. The formulation is extended in the subsequent sections to take into account ground water balance and its integration into an overall conjunctive use model.

The following additive type of production function is considered. It expresses the relative yield of a crop as a function of deficits suffered in the individual growth stages

$$
\frac{y}{y_{\max }}=1-\sum_{g=1}^{N G S} k y_{g}\left(1-\frac{A E T}{P E T}\right)
$$

where $y$ is the actual yield of the crop; $y_{\max }$ the maximum yield of the crop; $g$ the growth stage index; $N G S$ the number of growth stages within the growing season of the crop; $k y_{g}$ the yield response factor for the growth stage $g$; AET the actual and PET the potential evapotranspiration. The objective function used for optimally allocating water among the crops maximizes an integral measure of relative crop yield in the area. For multiple crops, the annual sum of the relative yields of all crops is taken as the integral measure to be maximized. The objective function used for the overall conjunctive use model is

$$
\operatorname{maximize} \sum_{c=1}^{N C}\left[1-\sum_{g=1}^{N G S} k y_{g}^{c}\left(1-\sum_{t \in g} \frac{A E T_{t}^{c}}{P E T_{t}^{c}}\right)\right]
$$

where $c$ is the crop index; $g$ the growth stage of the crop; $k y_{g}^{c}$ the yield response factor for the growth stage $g$ of the crop $c$; NGS the number of growth stages of the crop, and $N C$ the number of crops.

The optimization is to maximize sum of relative yields of crops in the reservoir command area. Optimization based on economic returns is not attempted. The model is meant for application to small canal command areas, where irrigated agriculture is heavily subsidized (such as in Iran) and the market prices do not reflect true marginal values to society. Hence an objective function based on physical outputs is preferred. The summation of AET and PET in Equation (2) is for the periods $t$, within the growth stage $g$, for the crop $c$. The objective function (Equation (2)) implies minimization of the weighted sum of the evapotranspiration deficits for the season.

The relative yield of a crop, $y / y_{\max }$, in Equation (1) would be equal to one if the volume of water available for the season is greater than or equal to the total crop water requirement in all the periods, thus permitting irrigation allocation to individual crops such that $A E T=$ $P E T$. Irrigation allocation is made in the present study whenever the soil moisture in the root zone is above the permanent wilting point and below the field capacity. The irrigation scenario used is to irrigate such that the soil moisture in the root zone is brought to the field capacity, to the extent possible depending on the water availability.

\subsubsection{Soil Humidity Balance}

The different elements considered in conceptualizing the soil moisture balance are shown in Figure 3.

The inputs to the model for a given period are the rainfall, irrigation water applied from surface and the aquifer, crop root depths at different times and the potential evapotranspiration. The outputs are the actual evapotranspiration during the period, deep percolation from the 


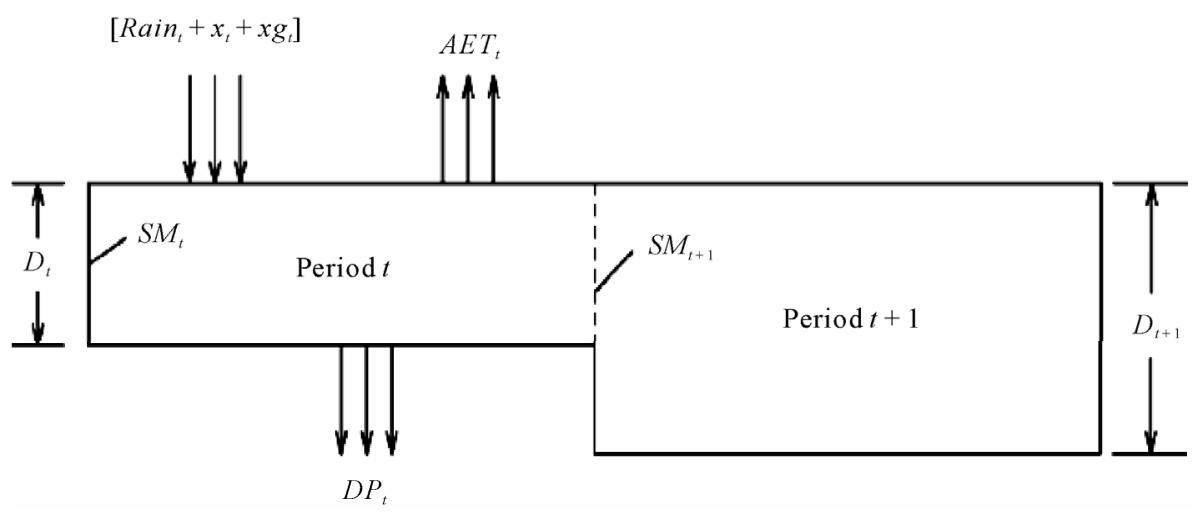

Figure 3. Soil moisture transition.

root zone during the period, if any, and the soil moisture in the root zone at the end of the period.

At the beginning of the first period of the season the soil moisture is assumed to be at field capacity, for all crops

$$
S M_{1}^{c}=S M_{\text {max }}^{c} \forall c
$$

where $S M_{1}^{c}$ is the available soil moisture(soil moisture above the permanent wilting point) at the beginning of the first period for the crop $c$; $S M_{\max }^{c}$ is the available soil moisture at the field capacity for the $\operatorname{crop} c$. The soil moisture balance equation for a given crop $c$ for any time period $t$ is given by

$$
\begin{aligned}
S M_{t+1}^{c} D_{t+1}^{c}= & S M_{t}^{c} D_{t}^{c}+x_{t}^{c}+x g_{t}^{c}+\text { Rain }_{t} \\
& -A E T_{t}^{c}-D P_{t}^{c} \forall c, t
\end{aligned}
$$

where $S M_{t}^{c}$ is the available soil moisture at the beginning of the period $\mathrm{t}$ for the $\operatorname{crop} c ; D_{t}^{c}$ the average root depth during the period $t$ for $\operatorname{crop} c ; x_{t}^{c}$ the irrigation allocation from surface water to crop c in period $t ; x g_{t}^{c}$ the irrigation allocation from ground water to crop c in period $t$; $\operatorname{Rain}_{t}$ the rainfall in period $t$, assuming that all the rain would contribute to enriching the soil moisture; $A E T_{t}^{c}$ the actual evapotranspiration during period $t$ for crop $c ; D P_{t}^{c}$ the deep percolation during the period $t$ for crop $c$.

The available soil moisture $S M_{t}^{c}$ and the maximum available soil moisture at field capacity $S M_{\max }$ are in depth units per unit root depth, $\mathrm{mm} / \mathrm{cm}$, and all other terms are in depth units, $\mathrm{mm}$. The available soil moisture in any time period $t$ for crop $c$ should not exceed the maximum corresponding to the field capacity of the soil

$$
\begin{aligned}
& S M_{t}^{c} \leq S M_{\text {max }}^{c} \forall c, t \\
& A E T_{t}^{c} \leq P E T_{t}^{c} \forall c, t
\end{aligned}
$$

where $P E T_{t}^{c}$ is the potential evapotranspiration during period $t$ for crop $c$. A linear relationship between AET/ $P E T$ and the soil moisture is maintained as per the fol- lowing constraint

$$
A E T_{t}^{c} \leq\left(\frac{S M_{t}^{c} D_{t}^{c}+x_{t}^{c}+x g_{t}^{c}+\text { Rain }_{t}}{S M_{\text {max }}^{c} D_{t}^{c}}\right) P E T_{t}^{c} \forall c, t
$$

The following constraints are imposed to see that whenever the deep percolation exists, the available soil moisture in the root zone of the crop at the end of the time period is at field capacity. In other words $D P_{t}>0$ only when $S M_{t+1}^{c}=S M_{\max }^{c}$ for any $t$. This is achieved by introducing integer variables, $\lambda$

$$
\begin{aligned}
& D P_{t}^{c} \leq \lambda_{t}^{c} G \forall c, t \\
& \lambda_{t}^{c} \leq \frac{S M_{t+1}^{c}}{S M_{\max }^{c}} \forall c, t
\end{aligned}
$$

where $\lambda_{t}^{c}$ is a binary ( 0 or 1 ) variable and $G$ is an arbitrarily large number.

\subsubsection{Reservior Water Balance}

Usable equation in reserviore simulation process is written on basis of mass conservation rule

$$
S(t)=S(t+1)-Q(t)+R(t)
$$

Unable bonds in intefrated simulatin process from reservoir include of reservoir volume limitations and amount of making free. Up and down limitations of reservoir volume obtained during of simulation process which enters as a bond to system by considering of flood water control volume and minimum useful volume of reserviore.

\subsubsection{Parameters of Stable Scenario}

The stable scenario is characterized by a set of parameters derived from results of the stable scenario for a normal year. The parameters considered are the proportion of the surface water application to total irrigation water, $r_{t}$, for each period, $t$, and the ratio of the actual to potential evapotranspiration, act, for a given crop in a given 
time period $t$, as obtained from the results of the optimization model for the identified stable scenario for a normal year

$$
\begin{gathered}
r_{t}=\frac{\sum_{1}^{N C} x_{t}^{c} \text { Area }_{c}}{\sum_{1}^{N C}\left(x_{t}^{c}+x g_{t}^{c}\right) \text { Area }_{c}} \\
a_{t}^{c}=\frac{A E T_{t}^{c}}{P E T_{t}^{c}}
\end{gathered}
$$

\subsubsection{Combination of Surface and Groundwater Modeling Results for Choosing the Stable Scenario}

For Simulation of reservoir activities, applying the relations of soil moisture balance and considering the relative crop yield in different scenarios, Programming language of Visual Basic was used. The Length period of modeling was 4 years which it changed from one dry year (in first year) to normal year gradually (in fourth year) as a rainfall and river discharge viewpoints. By studing the long term statistics of region, It was observed that in dryest year, entrance hydrologic amounts (rainfall and discharge of river) was $30 \%$ of long term average amounts. Thus, 4 year simulation from a dry year (which raining \& irrigation amounts is $30 \%$ of long term average amount) was begun and reached in fourth year to normal year gradually.

The conjunctive use model was prepared by specifying the model entrances consist of hydrologic situation (rainfall and discharge of river), agriculture data (plants potential evapotranspiration, root growth depth in different satges, the tillage area for each crops and $k_{c}$ ) and $r$ parameter (ratio of surface water to whole of irrigation water). Different scenarios are specified by defining different $r$ for model. Two kind of scenario was chosen in model:

1) Annual scenarios: The $r$ parameter was fixed in each scenario during the year

2) Seasonal scenarios: The year was devided to separated three seasons and $r_{1}, r_{2} \& r_{3}$ was defined for each scenario during the year

It was observed that the most and least amount of river discharge and rainfall in sufichay region was in spring and summer respectively. Fall and winter had the same condition. Also, spring and summer had the most irrigation requirement in term of temporal distribution. The irrigation requirement was fewer in fall and winter which its amount was the same in these two seasons. Therefore, the three periods in study area was fixed by considering the irrigation requirement, rainfall and discharge of river. Spring was the first period, summer the second, and fall and winter (together) were the third period.

\section{Results \& Discussion}

\subsection{Annual Selective Scenario}

The relative crop yield and water table draw down were calculated by using this program and available groundwater modeling software for each scenario (Table 3).

It was observed in Table 3, for keeping the allowable water table draw down in groundwater aquifer (allowable limitation of 3 meters), the minimum part of specified surface water is $\% 75$ for irrigation of arable lands. The purpose function rate (relative crop yield for all crops) increased and more draw down happened in water table by decreasing " $r$ ", as it is noticed. The most possible amount of purpose function was 13 (according to cultivation pattern in Maraghe plain), which could accessible in lieu of $r<=40$. In this condition, none of crops faced with shortage of irrigation requirement, but the minimum water table draw down reached to twice as much as its allowable amount, $6^{\mathrm{m}}$. The purpose function rate reached to the lowest amount of 10.2 out of 13 , if whole of irrigation requirement is supplied by using surface water resources (scenario $r=100$ ) and not falling in water table.

Thus, the scenario of number 6 (75 - 25) were chosen as a selective scenario. In scenario of $75-25$, the purpose function rate was 12.2 and water table draw down was 2.6, which was lower than allowable limitation.

The Figure 4 shows the storing volume changes during simulation period for selective scenario of 75:25. Also the Figure 5 presents the deficiency in crops water requirement for this scenario. The simulation period

Table 3. The relative crop yield and water table draw down

\begin{tabular}{|c|c|c|c|c|}
\hline No. & $\begin{array}{c}\text { Surface water } \\
\text { share (r) } \%\end{array}$ & $1-r$ & $\begin{array}{c}\text { Relative crop } \\
\text { yield }\end{array}$ & $\begin{array}{c}\text { Water table } \\
\text { draw down (m) }\end{array}$ \\
\hline 1 & 100 & 0 & 10.2 & 0 \\
\hline 2 & 95 & 5 & 10.71 & 0.5 \\
\hline 3 & 90 & 10 & 11.17 & 1.04 \\
\hline 4 & 85 & 15 & 11.56 & 1.6 \\
\hline 5 & 80 & 20 & 11.92 & 2.1 \\
\hline 6 & 75 & 25 & 12.2 & 2.6 \\
\hline 7 & 70 & 30 & 12.44 & 3.11 \\
\hline 8 & 65 & 35 & 12.72 & 3.6 \\
\hline 9 & 60 & 40 & 12.92 & 4.15 \\
\hline 10 & 40 & 60 & 13 & 6.23 \\
\hline 11 & 20 & 80 & 13 & 8.32 \\
\hline 12 & 0 & 100 & 13 & 10.41 \\
\hline
\end{tabular}
for different annual scenario. 


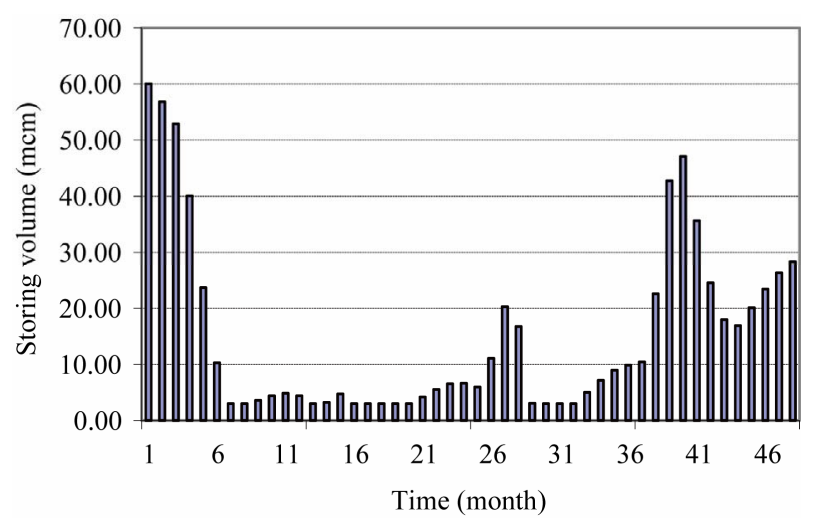

Figure 4. Storing volume changes in scenario of 75 - 25.

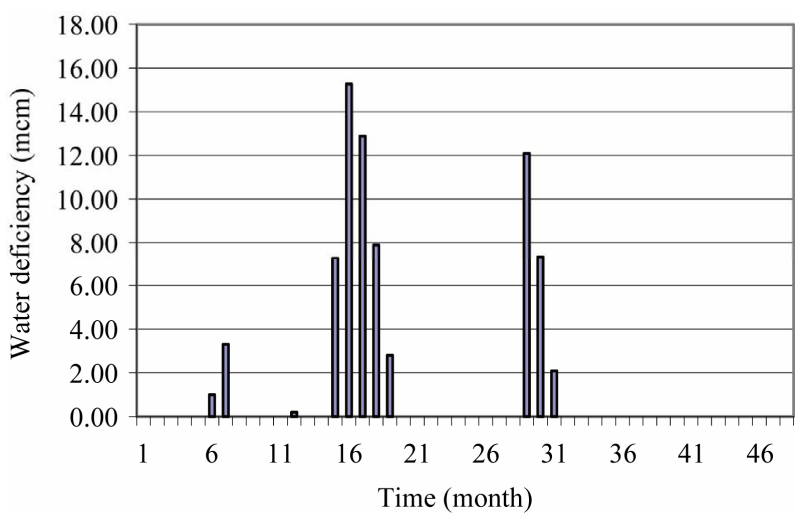

Figure 5. Water deficiency for scenario of 75 - 25.

started from dry year and reached to normal situation in forth year gradually. In first year, the river discharge was in minimum level, but water storing in reservoir was in high level (Smax) that could to relief the effect of drought in primary months of the first year. By going forward and near to the end of the year, the effect of drought became more severe.

Despite improvement in discharge of river in second year, by decreasing the storing volume, the impact of drought showed itself by crops water tension and the minimum volume (dead volume) happened in this year. In third year, the situation was better because of increase in discharge of river, but at the end of summer, water storing reached to dead volume that was the reason of deficiency in supplying the water requirement. In forth year, the normal situation came back and the amount of water was enough for requirement of arable lands. As a total, the general trend of water storing volume in each year was upward from begining to spring, and from end of spring to end of the year, it was downward.

\subsection{Seasonal Selective Scenario}

Table 4 presents the relative crop yeild and water table draw down in lieu of defined seasonal scenarios. The part of surface water in defined scenarios was proportion with each season. The water table changes and relative crop yield for different " $r$ " in seasons of year have been shown in Figures 6 and 7.

These seasonal scenarios were proportion with each season. It means that when rainfall and river discharge amount was low (in summer)," $r$ " was in lower level (more irrigation was met by groundwater) and when rainfall amount and discharge of river was high, " $r$ " was higher (the part of surface water was more). The maximum purpose of function for the selective scenario (that its water table draw down was lower than allowable limit), was 12.57 for scenario No. 3 (100-40-60), which it had $3^{\mathrm{m}}$ fall in watertable at the end of simulation. The defined " $r$ " for seasons of $1,2 \& 3$ should not be lower than amounts of $r_{1}>=100, r_{2}>=40$ and $r_{3}>=60$, till to have a allowable draw down in water table. Decrease of purpose function and water table draw down was observed by increasing the part of surface water in seasons of the year. The maximum amount of purpose function was 13, which happened for the first time in lieu of the scenario No. 8 (80-20-80) and the water table draw down was about 1.5 times as much as allowable amount in this scenario. According to the Table 4, it was noticed that purpose function was more sensitive to specified surface water in summer and spring respectively.

The Figures 8 and 9 show the storing volume changes and water deficiency during the simulation period for selective seasonal scenario of 100-40-60 respectively. As can be seen, the most tension and happening of water

Table 4. Relative crop yield and water table draw down for different seasonal scenarios.

\begin{tabular}{|c|c|c|c|c|c|}
\hline \multirow[b]{2}{*}{ No. } & \multicolumn{3}{|c|}{ Surface water share (r) } & \multirow{2}{*}{$\begin{array}{l}\text { Relative } \\
\text { crop yield }\end{array}$} & \multirow{2}{*}{$\begin{array}{c}\text { Water table } \\
\text { draw down (m) }\end{array}$} \\
\hline & Spring & summer & $\begin{array}{l}\text { Fall and } \\
\text { winter }\end{array}$ & & \\
\hline 1 & 100 & 40 & 100 & 12.44 & 2.54 \\
\hline 2 & 100 & 40 & 80 & 12.51 & 2.79 \\
\hline 3 & 100 & 40 & 60 & 12.57 & 3.04 \\
\hline 4 & 100 & 20 & 80 & 12.84 & 3.64 \\
\hline 5 & 100 & 20 & 60 & 12.89 & 3.89 \\
\hline 6 & 80 & 40 & 80 & 12.83 & 3.77 \\
\hline 7 & 80 & 40 & 60 & 12.88 & 4.02 \\
\hline 9 & 80 & 20 & 80 & 13.00 & 4.61 \\
\hline 10 & 80 & 20 & 60 & 13.00 & 4.87 \\
\hline
\end{tabular}




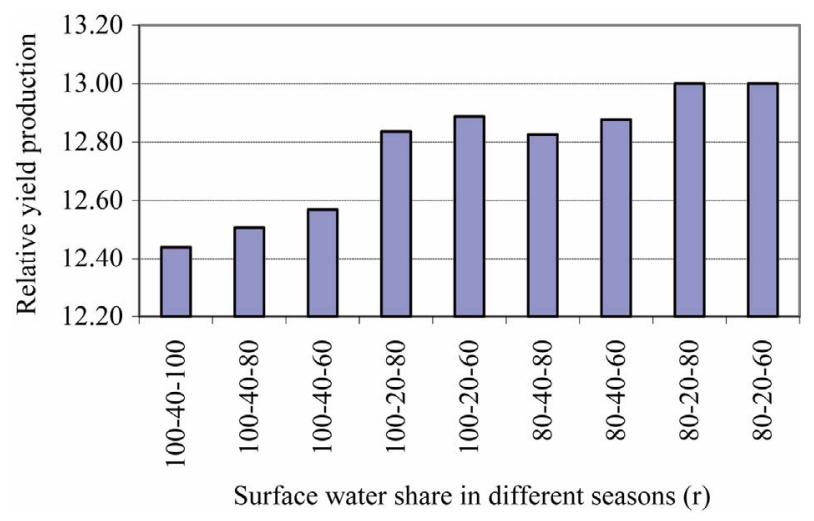

Figure 6. Relative crop yield production for different seasonal scenarios.

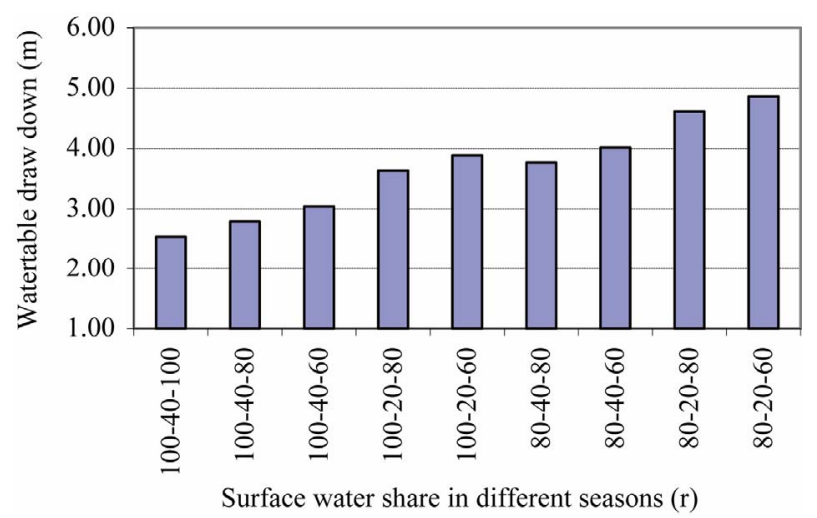

Figure 7. Water table draw down for different seasonal scenarios.

deficieny in simulation period for this scenario happend in spring and summer of the second and third years.

\section{Conclusions}

According to the results, it was noticed that performing of seasonal scenarios had a higher purpose function and Water table draw down was around 5\% more than allowable limit, which is negligible. Also it was found that surface water resources was not able to provide water requirement of arable lands, solitarily, and crops faced to more water shorages by only its applying. On the other hand, just the use of groundwater resources caused severe water table draw down which led to more problems for ground aquifer. The best way was conjunctive use of surface and groundwater resources to supply the irrigation requirements and preventing from heavy water table draw dawn in groundwater aquifer as well. Conjunctive use made this possibility to have the most crop yield from cultivatied lands by observance of allowable falling of water table in aquifer. Conjunctive use is a proper solution for our country plains which have been located in semi-arid region and surface water resources is not

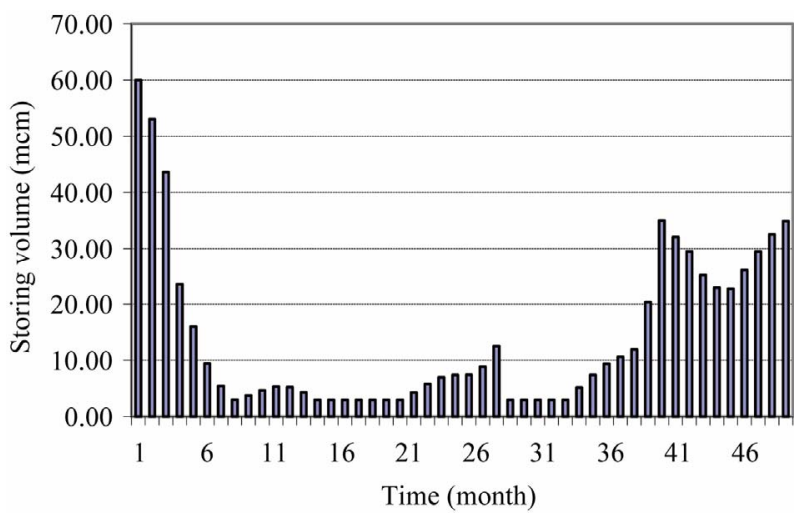

Figure 8. Storing volume changes for seasonal scenario of 100-40-60.

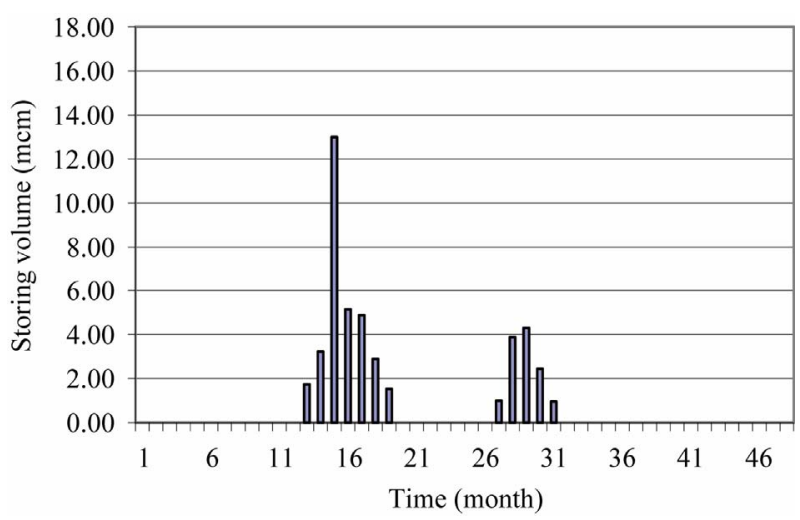

Figure 9. Water deficiency for scenario of 100-40-60.

only response of water demands.

In this research, the proportion of real yield operation to potential operation was used instead of economic purpose function, because the subsidize which is paid to agricultural inputs, don't let the possibility of real economic comparison in term of economic purpose function, and results showed this proposal method can be a proper choice. According to the hydrologic characteristics of region (rainfall and discharge of river), characteristics of agricultural lands (area, crops, real evapotranspiration of each crops) and reservoir characteristics which are determined by user, and also because of program capability for simulation of different defined policies during different temporal periods, this program ables to be performed for other plains of country which face to problems of surface water resources.

\section{Acknowledgements}

The authors appreciate the financial support of department of Irrigation and Reclamation Eng., university of Tehran. Also we whould like to thank the Dr. J. Nikbakht and Dr. K. Mohammadi for their helpful discussions and insightful comments. 


\section{References}

[1] J. J. Coe, "Conjunctive Use-Advantages, Constraints and Examples," Journal of Irrigation and Drainage Engineering, Vol. 116, No. 3, 1990, pp. 427-443. doi:10.1061/(ASCE)0733-9437(1990)116:3(427)

[2] A. S. Qureshi and I. Massih, "Managing Soil Salinity through Conjunctive Use of Surface Water and Ground Water: A Simulation Study," ICID Asian Regional Workshop, Chinese Taipei, 2003, pp. 233-247.

[3] M. S. Ejaz, and R. C. Peralta, "Maximizing Conjunctive Use of Surface and Groundwater under Surface Water Quality Constraints," Advances in Water Resources, Vol. 18, No. 2, 1995, pp. 67-75. doi:10.1016/0309-1708(95)00004-3

[4] M. Karamouz, R. Kerachian and B. Zahraie, "Monthly Water Resources and Irrigation Planning: Case Study of Conjunctive Use of Surface and Groundwater Resources," Journal of Irrigation and Drainage Engineering, Vol. 130, No. 5, 2004, pp. 391-402. doi:10.1061/(ASCE)0733-9437(2004)130:5(391)

[5] L. Upmanu, "Yield Model for Screening Surface and Groundwater Development," Journal of Water Resources Planning and Management, Vol. 121, No. 1, 1995, pp. 922. doi:10.1061/(ASCE)0733-9496(1995)121:1(9)

[6] C. Belaineh, R. C. Peralta and T. C. Hughes, "Simulation/ Optimization Modeling for Water Resources Management," Journal of Water Resources Planning and Management, Vol. 125, No. 3, 1990, pp. 154-161. doi:10.1061/(ASCE)0733-9496(1999)125:3(154)

[7] M. N. Azaiez and M. Hariga, “A Single-Period Model for Conjunctive Use of Ground and Surface Water under Severe Overdrafts and Water Deficit,” European Journal of
Operational Research, Vol. 133, No. 3, 2001, pp. 653666. doi:10.1016/S0377-2217(00)00212-5

[8] C. S. Jang and J. S. Chen, "Probabilistic Assessment of Groundwater Mixing with Surface Water for Agricultural Utilization," Journal of Hydrology, Vol. 378, 2009, pp. 188-199. doi:10.1016/j.jhydrol.2009.07.028

[9] V. Krysanova, F. Hattermann and A. Habeck, "Expected Changes in Water Resources Availability and Water Quality with Respect to Climate Change in Elbe River Basin,” Nordic Hydrology, Vol. 36, No. 4-5, 2005 pp. 321-333.

[10] J. Scibek, D. M. Allen, A. J. Cannon and P. H. Whitfield, "Groundwater-Surface Water Interaction under Scenarios of Climate Change Using a High Reolution Transient Groundwater Model,” Journal of Hydrology, Vol. 333, 2007, pp. 165-181. doi:10.1016/j.jhydrol.2006.08.005

[11] J. Nikbakht, "Optimum Conjunctive Use of Surface Water and Groundwater in Condition of Water Qualitative and Quantitative Limitation for Producing Maximum Crop Yield,” Doctoral Thesis, University of Tarbiat Modarres, Tehran, Iran, 2006.

[12] Mahab Ghodss Consulting Eng. Company, "Summery of Alavian Dam Report,” Tehran, Iran, 1994.

[13] P. V. Manuel, A. Joaquin and S. Andres, "Economic Optimization of Conjunctive Use of Surface Water and Groundwater at the Basin Scale," Journal of Water Resources Planning and Management, Vol. 132, No. 6, 2006, pp. 454-467. doi:10.1061/(ASCE)0733-9496(2006)132:6(454)

[14] S. Vedula, P. P. Mujumdar and G. C. Sekhar, "Conjunctive Use Modeling for Multicrop Irrigation,” Journal of Agricultural Water Management, Vol. 73, 2005, pp. 193221. doi:10.1016/j.agwat.2004.10.014 